\title{
Relationship Between Country Income And View Toward Work
}

\author{
Constance Bates, (Email: batesc@fiu.edu), Florida International University
}

\section{INTRODUCTION}

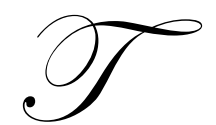

his paper examines the relationship between income and the view toward work. That is, countries are compared based on per capita income and survey results showing how work is viewed. The hypothesis is that high income countries value work more than low income countries. Furthermore, it is hypothesized that low income countries value something, other than work, more than high income countries. The reasoning is that rich countries are rich because they value work and poor countries are poor because they value something else more than work. Per capita income data is taken from the World Bank. The data on values is taken from the World Values Survey and the European Values Survey (WVS/EVS).

\section{LITERATURE SEARCH}

There is a great deal of research regarding the issues of cultural values and income. In fact, Kraus (1995) cites 85 studies trying to explain the relationship between cultural values and economic behavior. The cross-cultural literature is anchored by Geert Hofstede and Andre Laurent. They launched large, multi-country studies to identify differences in cultural values. They built models categorizing countries, along with researchers like Trompenaars who continued to identify and categorize country-based cultural values. But they stopped short of explaining the link between values and income.

Another line of research was the approach of economists to define the relationship between culture and economic development. This research is characterized by Max Weber a hundred years ago, who wrote that Protestant Europe developed faster economically than their Catholic counterparts because they had different cultural values. There followed more research by Rostow (1960), Hoselitz (1958), and Hoselitz (1963), and Kuznets (1965) to show that values determine economic development. Then Putnam (1993) and Fukuyama (1995) wrote books promulgating the idea that cultural values explain economic growth. Since then a number of studies have been done to explore the relationship between culture and other outcomes, such as productivity, political instability, and management styles. Harrison and Huntington (2000) produced a book summarizing the studies on this subject, not only by economists, but also sociologists and political scientists as well.

A third line of research appears in the areas of sociology and political science. This line of inquiry also began with Weber's book, but focuses more on social and individual factors like motivation. It includes works by Tawney (1926, 1955), Harrison (1992), McClelland et al (1953), and McClelland (1961), on achievement motivation. Inglehart (1971), (1977), (1990), (1996), and (1997) pursued the importance of achievement motivation. Both McClelland and Inglehart used indirect variables like story content and values parents want to teach children. Some have questioned whether these variables are good representatives of the achievement drive. These authors concluded there was a positive correlation between achievement motivation and economic development. Both researchers added another causal factor to economic development: trust.

Also, Inglehart describes an interesting phenomenon: he identifies post-materialistic syndrome (1977). When a country achieves a high enough level of economic development, the economic changes produce cultural changes. So not only does the culture change the economy, but the economy changes the culture.

Others continue to test the multi-factor models. Marini (2004) found achievement and trust explain economic development, and economic development changes culture, but it depends on the stage of economic development. The relationship changes during different economic stages. Pryor (2005), however, conducted a study 
correlating cultural values and economic success over a two decade period and concluded that cultural values do not cause economic growth. Even after all this research in sociology, political science, and economics, there is still no consensus on the relationship between cultural values and income.

This paper continues the search for the answer to the question, do values determine wealth? Specifically, this paper focuses on just one variable, unlike the large models of the cross-cultural researchers. It compares two large groups of countries: low income and high income, unlike the economic research. Also, the data is the direct viewpoint of respondents in a survey, unlike the story content research of the sociologists. In short, this paper compares low income countries with high income countries on the basis of their answer to the question: How important is work in your life?

\section{THE SURVEY AND DATA}

The source for the income data is from the World Bank, for the year 2000. It is gross national income per capita, using the Atlas method. The source for the classification system of low income, lower middle income, upper middle income, and high income is the World Development Indicators database, 2000, World Bank. Table 1 shows income per capita for the countries in the study.

Table 1: Country Income (GNI) Per Capital (\$) Source: World Bank, 2000

\begin{tabular}{|c|c|c|c|c|c|c|c|}
\hline Low Income & $\$ 0-754$ & $\begin{array}{l}\text { Low Mid } \\
\text { Income }\end{array}$ & $\$ 756-2,995$ & $\begin{array}{l}\text { Upper Mid } \\
\text { Income }\end{array}$ & $\$ 2,996-9,264$ & $\begin{array}{c}\text { High } \\
\text { Income }\end{array}$ & $\$ 9,265$ up \\
\hline Georgia & 700 & Domin. Rep. & 2,170 & Argentina & 7,470 & Luxembourg & 43,560 \\
\hline Ukraine & 700 & Colombia & 2,060 & Uruguay & 6,150 & Switzerland & 40,110 \\
\hline Armenia & 660 & Peru & 2,050 & Czech Rep. & 5,690 & Norway & 35,660 \\
\hline Azerbaijan & 610 & El Salvador & 2,000 & Mexico & 5,110 & Japan & 35,140 \\
\hline Indonesia & 590 & Macedonia & 1,850 & Chile & 4,860 & US & 34,400 \\
\hline Moldova & 370 & Jordan & 1,760 & Hungary & 4,670 & Denmark & 31,460 \\
\hline Pakistan & 480 & Romania & 1,690 & Croatia & 4,500 & Iceland & 29,960 \\
\hline India & 450 & Iran & 1,670 & Poland & 4,430 & Sweden & 28,650 \\
\hline Vietnam & 380 & Bulgaria & 1,600 & Venezuela & 4,100 & Austria & 26,010 \\
\hline Nigeria & 280 & Algeria & 1,570 & Estonia & 4,070 & Germany & 25,510 \\
\hline Zimbabwe & 460 & Egypt & 1,460 & Slovakia & 3,870 & Netherlands & 25,200 \\
\hline Bangladesh & 390 & Belarus & 1,380 & Brazil & 3,590 & Finland & 24,920 \\
\hline Tanzania & 280 & Bosnia Herz. & 1,290 & Latvia & 3,190 & Belgium & 24,900 \\
\hline \multirow{13}{*}{$\begin{array}{c}\text { Uganda } \\
\mathrm{n}=14\end{array}$} & 260 & Morocco & 1,220 & Lithuania & 3,170 & France & 24,470 \\
\hline & mean $=$ & Albania & 1,180 & S. Africa & 3,050 & Ireland & 22,990 \\
\hline & 472 & Philippines & 1,040 & Turkey & 2,980 & Singapore & 22,890 \\
\hline & & $\begin{array}{c}\text { Serbia \& } \\
\text { Mont. }\end{array}$ & 960 & Russia & 1,710 & Canada & 21,810 \\
\hline & & China & 930 & $\mathrm{n}=17$ & mean $=$ & Italy & 20,160 \\
\hline & & $\mathrm{n}=18$ & mean $=$ & & 4,271 & Australia & 20,060 \\
\hline & & & 1,549 & & & Spain & 15,320 \\
\hline & & & & & & New Zeal. & 13,680 \\
\hline & & & & & & Greece & 11,290 \\
\hline & & & & & & Portugal & 10,940 \\
\hline & & & & & & Slovenia & 10,640 \\
\hline & & & & & & S. Korea & 9,800 \\
\hline & & & & & & $\begin{array}{l}\text { Malta } \\
n=26\end{array}$ & $\begin{array}{c}9,540 \\
\text { mean }=\end{array}$ \\
\hline
\end{tabular}

The World Values Survey and European Values Survey are large, publicly available databases covering 81 societies, which include $85 \%$ of the world's population. They were created by social scientists in Europe and have 
been expanded to include researchers all over the world. The surveys were conducted in successive waves: 1990-91, 1995-96, and 1999-2001. The data for this study is mostly from the last wave, 1999-2001. But for 13 countries, (Armenia, Australia, Azerbaijan, Brazil, Colombia, Dominican Republic, El Salvador, Georgia, New Zealand, Norway, Switzerland, Taiwan, and Uruguay) the data is from the 1995 wave. The sample sizes varied but were at least 1,000 per country.

The survey asked questions covering many values: environment, work, family, politics, religion, and national identity. Also included are questions about happiness, child-rearing, friends, neighbors, and volunteering, among other issues. There were six questions asking respondents to rate how important each value was in their lives. The basic question was: "For each of the following aspects, indicate how important it is in your life" followed by one of the following: family, friends, leisure, politics, work and religion.

\section{RESULTS}

It is hypothesized:

- $\quad$ High income countries value work more than low income countries.

- Low income countries value something, other than work, more than high income countries.

It is expected that high income countries value work more than low income countries because one can see the results of their efforts: rich, developed economies. It is expected that low income countries don't value work as much and place emphasis on something other than work. This would explain why the results of their efforts produce less wealth.

\section{Work And Income}

In order to address the first hypothesis, work and income data are presented together. The countries from WVS/EVS are grouped into 4 income categories (following the classification system of the World Bank): low, lower middle, upper middle, and high income. The results presented in the tables are the percent of respondents selecting the category "Very Important." The work values from the survey are then averaged for each income category. When these means are compared, one can clearly see a difference between each income group. Table 2 shows the mean view toward work of low income countries is 72.5, much higher than the mean of high income countries 55.5. In comparing the means of the low and high income group, the data does not support hypothesis 1 . In fact, the data shows the opposite: high income countries value work less than low income countries.

Table 2: Income And Value Toward Work

\begin{tabular}{ccccc}
\hline $\begin{array}{l}\text { Average \% of } \\
\text { Respondents: }\end{array}$ & Low Income & Low Middle Income & Upper Middle Income & High Income \\
\hline "Very Important" & 72.5 & 72.32 & 68.94 & 55.5
\end{tabular}

\section{Work Harder}

This suggests that work has a higher priority in low income countries than high income countries. People earn less in low income countries, so they have to work harder and longer to support themselves. Consequently, they spend more time and energy on work than those in high income countries. As a result, work is a bigger part of daily life in low income countries. In high income countries, on the other hand, work is not considered as important as it is in the low income countries. They devote less time and energy to work in daily life than in low income countries. In other words, the proportion of the day devoted to work is smaller in a high income country. 


\section{Fewer Job Alternatives}

Another reason work is more important in a low income country is that few alternative work opportunities exist. If one can't work on the farm, what else is there? If there is one factory in town and one loses their job, what else is there? If one loses a job in a small, closed community, who will hire you?

Not only are there fewer alternatives, but the worker has fewer resources to access new jobs. These workers probably don't have automobiles to drive to other farms or factories or stores. There is a limit to how far one can go on a bus or a bicycle day after day.

Another characteristic of labor in low income countries is the lack of labor skills. When workers lack skills, their ability to qualify for alternative jobs is limited. If there is a three year drought and the farms shut down, the worker has to learn how to work in a factory, and is competing with all the other farm laborers out of work. The reverse is true; if a factory shuts down, then all the factory workers are out of work and looking for work on the farms. Not only do they not have the farming skills, they are competing with all the other laid-off factory workers. The lack of these three things - alternative jobs, transportation, and skills - augments the need to work hard and keep one's job. This could explain why low income countries view work as more important.

\section{Need for Supplemental Income}

Another reason low income countries view work as more important is that every bit of their low income is critical for survival. Low income workers do not have much money left over for luxuries; they need every dollar they earn to buy food and shelter. Consequently, they would be likely to work harder or longer and make more sacrifices in their daily lives in order to work. Also, they may constantly be looking for additional work opportunities in order to earn a little more money. These could take the form of selling garden produce, eggs or dairy, preserving foods, sewing, or providing services, such as cleaning homes, washing clothes, babysitting, or transporting people or goods. It is not uncommon for workers in low income countries to have multiple jobs or sources of income. In fact, it is often expected that children work and bring money into the household.

On the other hand, high income countries have a much higher productivity rate which means that 40 hours of labor produces a lot more than in a low income country. So it is common in high income countries for people to work 40 hours a week and no more. They may not work overtime and may not look for other ways to supplement their income. They may be earning enough to live on with one job and do not need to work more. As a result, high income earners do other things with their time and energy beyond the forty-hour workweek. They exercise, develop interests in collecting, have hobbies, or spend more time with family. This would explain why high income countries view work as less important: it is not as big a part of their day.

\section{View Toward Work and National Income}

There is still the question, then, of how the view toward work affects the national income. If workers in a high income country value work less than a low income country, why do they produce a higher national income? If workers in a low income country value work more, why don't they produce more national income? With everyone working harder and working additional jobs to supplement their income, why doesn't this add up to greater national income?

The high income workers are more productive. They have more education, which leads to more technology, and more efficient use of resources. So the high income workers aren't working harder, they are working smarter. With limited education and training, the low income workers are unable to use more sophisticated machines or techniques so their productivity remains low.

The high income workers accept change easier and can readily adopt new, more efficient ways of working. The low income workers are working harder but they are doing the same thing in the same way, day after day. 
Always relying on tradition as a guide to decision making can prevent workers from finding a better way of doing things.

The high income workers engage in higher risk-taking. This search for new ways of doing things ultimately leads to finding a better way. Many low income countries are risk averse. Their view is that it is a waste of resources to try something that has never been done before: it might fail and all the resources would be lost. In a scarce resource economy, wasting resources is an economic sin. Consequently, new approaches are avoided. Without education, technology, change, or risk-taking, low income workers cannot improve their national income. They work hard each year, do everything the same way each year, produce the same amount each year, and national income doesn't grow each year. Further research would have to be conducted to further examine the relationship between income and education, technology, change, and risk-taking.

\section{FAMILY AND INCOME}

Hypothesis 2 proposes that low income countries value other things more than work. Other values that could be examined are view toward family, friends, leisure, politics, and religion. The WVS/EVS survey reported on the percent of people who thought "Family" was very important in their lives. Table 3 shows data from this question organized into high and low income groups. The column of numbers shows the percent of each country's respondents who rated "Family" as Very Important. When the numbers of each income group are averaged, it does not show a meaningful difference. Both income groups value family about the same: low income (91.29) and high income (88.15). This may come as a surprise to many people. But these numbers show there is no substantial difference between the income groups. A remarkable note is that the numbers are so high for "Family." Taking a look at other variables, one can see all the means for 6 variables. The highest numbers, by far, are the means for "Family." Not only do the income groups agree on "Family" as Very Important, they also agree that it is more important than any of the other variables.

\section{POLITICS AND INCOME}

Table 3 also shows respondents' views toward "Politics." The WVS/EVS survey reported on the percent of people who thought "Politics" was very important in their lives. Table 7 shows data from this question organized into high and low income groups. The column of numbers shows the percent of each country's respondents who rated "Politics" as Very Important. When the numbers of each income group are averaged, it does not show a meaningful difference. The mean for low income countries is 46.43 and for high income countries is 40.04; about the same percent of people in each income group rate "Politics" as Very Important. Politics does impact work; it affects taxes, regulations, and the rules for doing business. Laws can even be passed to regulate wages, prices, and ownership in certain industries. In international operations, it can affect whether a firm can send profits home, whether foreigners can own a business, what products/services can be exported/imported, and who can own natural resources. Each of these issues can have an important impact on workers and business operations. It seems people in both the developed and less developed economies equally recognize the impact of politics on their lives.

\section{FRIENDS AND INCOME}

Since family is so important, how important are friends? Table 3 shows country data from WVS/EVS grouped by income. The column of numbers shows the percent of each country's respondents who rated "Friends" as Very Important. The mean for how low income countries rated "Friends" as Very Important is 43.07. The mean for high income countries is 50.04. Although there is a little difference, it is probably not a meaningful difference. This means both income groups rate "Friends" about the same. It is also interesting to note the means are about half as high as the means for "Family." Clearly, friends are not as important as family in these income groups. 
Table 3: Summary Table - Income And Values

\begin{tabular}{lcc} 
Values & Low Income & High Income \\
\hline Religion & 59.14 & 22.58 \\
Work & 72.5 & 55.5 \\
\hline Leisure & 25.57 & 38.92 \\
Friends & 43.07 & 50.04 \\
\hline Politics & 46.43 & 40.04 \\
Family & 91.29 & 88.15 \\
\hline
\end{tabular}

\section{LEISURE AND INCOME}

Table 3 shows countries' views toward "Leisure" grouped by income. The WVS/EVS survey reported on the percent of people who thought "Leisure" was Very Important in their lives. Table 8 shows data from this question organized into high and low income groups. The column of numbers shows the percent of each country's respondents who rated "Leisure" as Very Important. Not surprisingly, given the earlier results about view toward work, low income countries valued leisure less (25.57) than high income countries (38.92). This reinforces the data from the view toward work. In low income countries, work is more important and leisure is less important. The opposite holds true for high income countries. It makes sense that leisure would be viewed as less important in countries where people have to work harder and look for ways to supplement their income. If one is working harder and longer, then leisure becomes a luxury that is seldom afforded. For the high income countries with their rising productivity, workers are continually finding more free time and look for ways to use it.

\section{RELIGION AND INCOME}

In the WVS/EVS survey, respondents were asked how important "Religion" was in their lives. Table 3 shows data from this question organized into high and low income groups. The numbers show the percent of respondents who rated "Religion" as Very Important. More low income countries found it was Very Important than high income countries. Table 3 shows the mean for low income countries was 59.14 and for high income countries it was 22.58. This is a substantial difference. This could be explained by the lack of education common in low income countries and the over-reliance on explanations from non-scientific sources. Tradition and folk tales supply a lot of answers in low income countries. In addition, these sources, tradition, religion, and folk tales, may also supply guesses about the future. If this is so, then religion would be quite a bit more important in such a society. It could explain the unexplainable and provide a mental structure for how to interpret the world and feel confident about the future. By the same token, for educated, high income countries, a belief in scientific method (cause and effect) induces feelings of confidence. Hence, the reliance on religion is less in high income countries.

\section{SUMMARY OF TABLE 3}

The data supports Hypothesis 2, low income countries do value something other than work more than high income countries. They value religion more than high income countries; 59.14 vs. 22.58 . This is one of the most interesting results of this research. It appears that religion could be a better predictor of country income than view toward work. More research needs to be done to learn more about this relationship.

\section{INDICATIONS FOR INTERNATIONAL MANAGERS}

\section{View Toward Work}

\section{Greater Impact}

Since there are substantial differences regarding view toward work and religion, managers going abroad may want to modify the way they manage. Focusing first on view toward work, low income workers place a greater 
emphasis on their work. It fills a larger part of their life. This implies that foreign managers be aware that things that happen at work have more impact in low income countries than high income mangers are used to. For example, a negative experience, like criticism from the boss, may be viewed much more seriously in a low income country. The consequences of disappointing the boss are more severe, and as discussed earlier, the opportunities to find other employment are more limited than in high income countries. Managers in low income countries need to recognize that communication from the boss and changes at work can be magnified in the employee's mind.

\section{Fear of Change}

Low income countries are traditional societies, looking to the past for guidance. They generally view change with suspicion. Changes at work that have nothing to do with an employee's job may still be viewed in a negative way. A change in pay, status, or work schedule could be viewed as threatening to a low income worker. In fact, change itself could be viewed as a portent of future loss of job or security to a low income worker. When high income country bosses make changes, which they consider a common practice, they are amazed when low income country workers quit. For the low income worker, meeting the expected disaster (being fired) head on feels better than waiting for the axe to fall. The foreign manager needs to take the fear of change into account and introduce change slowly and with a lot of communication about the reason for the change.

\section{Different Communication}

Managers should be prepared to find workers in low income countries taking communication, both verbal and nonverbal, more seriously. The low income country workers are constantly looking for cues as to their job status. Managers should be self-conscious when communicating in low income countries. They should be clear, specific, and tactful, taking care to insure the worker does not jump to conclusions and overreact or react negatively beyond what is warranted. They may need to take efforts to make workers feel more secure, especially when change is taking place. Otherwise, low income workers may just leave, because they feel uneasy.

Another way in which communication may be different is in the way constructive criticism is handled. Where work is a bigger part of one's life, every little comment can be scrutinized. Care must be taken to point out positive aspects often. In fact, it may be a good idea to not use constructive criticism at all. It may be better just to keep training and communicating and rewarding and training. Negative comments about performance may trigger the desire to leave before being fired.

Perhaps most importantly, low income countries often have two communication characteristics which high income countries need to adopt. They are face-saving and indirect communication. Face-saving is the need to always preserve another person's dignity in a conversation and never embarrass anyone in front of others. Indirect communication means bad news is delivered in an indirect way. Instead of saying, "this department's performance is lower than last year," the manger may say, "we are so fortunate to have a seminar where we can learn the latest techniques."

\section{Training}

The fourth aspect of adapting to low income country workers is to consider their plight in finding new jobs. Since work is so important and new jobs are so rare in low income countries, managers can help keep workers by investing more in training. Additional training improves productivity in the factory (or farm or store). It also motivates workers to stay with employers who help them improve their skills. Job security is more important in low income countries than high income countries.

\section{View Toward Leisure}

Managers coming from high income countries need to make adjustments regarding leisure when they go to low income countries. Where work is viewed as more important, and leisure is viewed as less important, managers may need to reconsider the reward system. While it is common in a high income country to reward with days off, 
fringe benefits, and memberships in exercise clubs, it would not be a good idea to take this approach in a low income country. It may make more sense to focus on pay and job security.

\section{View Toward Religion}

The other value in which the income groups differed was religion. The low income countries valued religion quite a bit more than high income countries. For the foreign manager, this means that a basic understanding of the local religion is essential. It is not a good idea to adopt the local religion; in fact, that is a bad idea and will be viewed as an act of insincerity. But by understanding the basic ideas, one can help the worker be more comfortable working for a foreign manager and more confident that he can have his religion and his job, too. This means the foreign manager must observe the religious holidays and let workers off when they would normally be off in a local firm. It may mean that pictures or symbols need to be displayed in the workplace, to show respect for the local belief system. Seldom is a foreign manager asked to take part in a religious ceremony, but often the manager needs to allow a prayer or ceremony to take place. The more respectfully the foreign manger can do this, the better. For example, it may be common practice to have a religious ceremony when a new business or factory or store is opened. The manger will not be expected to officiate, but will be expected to allow the ceremony to take place and attend. The key is to create a work environment similar to local firms with regard to religious practices.

It will help motivate the foreign manager to remember how high the low income workers view religion (59.14). So it is in the foreign manger's best interests to allow workers to follow their traditions and religious customs in the workplace. The customs may be a combination of religious and non-religious customs, similar to our Christmas customs.

Sometimes the manager may be asked to attend a wedding or graduation or some kind of ceremony that is only partly religious. It is important the manager attend these "outside" functions. They are very important to low income country workers and they will be very disappointed if the boss is invited and does not attend. The worker will lose face. High income managers may feel these "outside" functions are not work-related and there is no need to attend. But it is often the custom to blend work and family and religion and socializing in low income countries. If the boss is invited and does not attend, it may seem like the boss has a negative view of the employee and the employee may quit soon after the ceremony, thinking he is not in very good standing with the boss anyway.

\section{View Toward Family}

The high means for rating the importance of "Family" could have an impact at work. The manager can expect that low income country workers will want to incorporate their family goals into their jobs. For example, workers will want to hire members of their families when positions open up. The employer can expect workers to place family needs over their job needs. A worker may say, "I had to take care of my sick grandmother yesterday, I couldn't come to work." Workers may have to take time off from work to help bring the crops in at the family farm. Foreign managers will have to adapt and accept that families will often come first for workers in low income countries. To be effective, the managers can find ways to cope with this phenomenon. For example, they may find that it pays to re-hire workers who have left for family emergencies or to help on the farm. Managers may have lower training costs if they hire former employees. At the same time, responsibility for family may help make workers more concerned about keeping their jobs and treating the boss with respect. If the manager can make the worker feel secure and feel that he is treated with respect, this may help in worker retention.

\section{FUTURE RESEARCH}

The underlying research question remains: what makes rich countries rich? It was anticipated that research would show that rich countries are rich because people value work more and work harder and it all adds up to greater income. But the WVS/EVS survey does not support this hypothesis. Low income countries valued work more, said it was more important in their lives. So if view toward work and country income do not go hand-in-hand, what is paired up with income? 
Future research could be directed to examine this issue by looking at the suggestions in the section "Indications for International Managers." Education is a logical place to begin. Is country income correlated with education? Are high school diplomas and college degrees essential for economic development? Level of technology may be correlated with country income. Can countries only develop when they adopt technological advances? View toward change and risk-taking may be correlated with country income. It is expected that view toward change would be highly correlated with country income. This would explain why low income workers work harder and have less income and high income country workers work less hard and have higher income: it depends on productivity improvements. Risk-taking may also be an important variable in predicting country income. It may be that a cluster of these variables accurately predict income.

Research can be done on how managers can best adapt. For example, what can be done to reduce the high turnover rate in low income country employment? One could formally examine the question: does hiring former employees reduce turnover and training costs? One could formally examine the communication issue. Research could be done on communication patterns in low and high income countries. If we knew more about effective communication practices then we could better advise our traveling managers how to adapt. For example, does adopting indirect communication practices reduce employee turnover? A study could be done to examine the question: does increased investment in training affect company profits? Does hiring fellow family members reduce employee turnover?

One result from the research was the high mean for view toward religion in low income countries. Future research could be directed to study this more carefully. There was such a large difference in means between low income and high income countries, this variable may be a great contributor in predicting income. Also, it would be interesting to know if specific religions are related to high or low income.

\section{SUMMARY}

Comparing income groups on the basis of view toward work revealed some surprises. The first hypothesis, high income countries value work more than low income countries, was not supported by the data. In fact the data showed that high income countries value work less than low income countries. This was surprising as it was expected that view toward work would be paired with country income. Future research is suggested to identify the variables that are correlated with country income. Some possibilities are: education, technology, change, and risk-taking.

The second hypothesis, low income countries value something other than work more than high income countries, was supported by the data. Low income countries valued religion more than low income countries. The results of this study help international managers prepare for foreign assignments. If they are going to low income countries, they should realize work and religion are more important there. With regard to work, managers should use tactful, face-saving communication, introduce change carefully, and avoid creating an insecure work environment. With regard to religion, managers should follow local customs in the interface between religion and work. Also, managers should honor social invitations and recognize their workers' family obligations.

\section{REFERENCES}

1. Fukuyama, F. (1995). Trust: The Social Virtues and the Creation of Prosperity. New York: Free Press.

2. Granato, Jim, Ronald Inglehart, and D. Leblang. (1996). The Effect of Cultural Values on Economic Development: Theory, Hypotheses, and Some Empirical Tests. American Journal of Political Science, 40(3): 607-631.

3. Hampden-Turner, Charles and Fons Trompenaars. (1993). The Seven Cultures of Capitalism. New York: Currency Doubleday.

4. Harrison, L. E. and S. P. Huntington, Editors. (2000). Cultural Matters: How Values Shape Human Progress. New York: Basic Books.

5. Hofstede, Geert. (1980). Cultures Consequences. Beverly Hills, CA: Sage.

6. Hofstede, Geert. (1991). Cultures and Organizations: Software of the Mind. New York: McGraw-Hill. 
7. Hoselitz, B. F. (1960). Theories of Stages of Economic Growth. In B.F. Hoselitz et al., editors, Theories of Economic Growth. Glencoe, IL: Free Press.

8. Hoselitz, B. F. (1963). Main Concepts in the Analysis of the Social Implications of Technical Change. In B. F. Hoselitz and W. E. Moore, Editors, Industrialization and Society, UNESCO, Mouton.

9. Inglehart, Ronald. (1971). The Silent Revolution in Europe. American Political Science Review 4: 991 1017.

10. Inglehart, Ronald. (1977). The Silent Revolution: Changing Values and Political Styles. Princeton, NJ: Princeton University Press.

11. Inglehart, Ronald. (1990). Culture Shift in Advanced Industrial Society. Princeton, NJ: Princeton University Press.

12. Inglehart, Ronald. (1997). Modernization and Postmodernization: Cultural, Economic, and Political Change in 43 Societies. Princeton, NJ: Princeton University Press.

13. Inglehart, Ronald, Miguel Basanez, and Alejandro Moreno. (2000). Human Values and Beliefs: A CrossCultural Sourcebook. Ann Arbor: University of Michigan Press.

14. Inglehart, Ronald, Miguel Basanez, Jaime Diez-Medrano, Loek Halman, and Ruud Luijkx (eds.). (2004). Human Beliefs and Values: A Cross-cultural Sourcebook Based on the 1999-2002 Values Surveys. Mexico: Siglo Veintiuno Editores.

15. Kraus, Stephen J. (1995). Attitudes and the Prediction of Behavior: A Meta-analysis of the Empirical Literature. Personality and Social Psychology Bulletin 21(1): 58-75.

16. Kuznets, S. (1965). Economic Growth and Structure. New York: W. W. Norton \& Co.

17. Laurent, Andre. (1983). The Cultural Diversity of Western Conceptions of Management. International Studies of Management and Organization. XIII(1-2).

18. Laurent, Andre. (1986). The Cross-Cultural Puzzle of International Human Resource Management. Human Resource Management 25(1).

19. Laurent, Andre. (1991). Cross-cultural Management for Pan-European Companies. Europe 1992 and Beyond. Sypros Makridakis, ed. San Francisco: Jossey-Bass.

20. Marini, Matteo. (2004). Cultural Evolution and Economic Growth: a Theoretical Hypothesis with Some Empirical Evidence. Journal of Socio-Economics 33(6): 765-784.

21. McClelland, David, et al. (1953). The Achievement Motive. New York: Appleton-Century-Crofts.

22. McClelland, David. (1961). The Achieving Society. Princeton, NJ: Van Nostrand.

23. Pryor, Frederic L. (2005). National Values and Economic Growth. The American Journal of Economics and Sociology 64(2): 451-483.

24. Putnam, R. (1993). Making Democracy Work: Civic Traditions in Modern Italy. Princeton NJ: Princeton University Press.

25. Rostow, W. W. (1960). The Process of Economic Growth. $2^{\text {nd }}$ ed. New York: W. W. Norton \& Co.

26. Trompenaars, Fons. (1993). Riding the Waves of Change. London: Economist Books.

27. Trompenaars, Fons and Charles Hampden-Turner. (1998). Riding the Waves of Culture. New York: McGraw-Hill.

28. Weber, Max. ([1904-1905] 1976 ed.). The Protestant Ethic and the Spirit of Capitalism. London: Allen \& Unwin.

29. World Bank. (2000). World Development Indicators. World Bank. 